\title{
GEOLOGIC MAP OF THE CORONA NORTH 7.5' QUADRANGLE, RIVERSIDE AND SAN BERNARDINO COUNTIES, CALIFORNIA
}

\author{
By Douglas M. Morton ${ }^{1}$ and C.H. Gray, Jr. ${ }^{2,3}$ \\ Digital preparation by Kelly R. Bovard ${ }^{1}$ and Michael Dawson ${ }^{1}$ \\ Prepared in cooperation with \\ CALIFORNIA DIVISION OF MINES AND GEOLOGY
}

Open-File Report OF 02-22

2002

Any use of trade, product, or firm names is for descriptive purposes only and does not imply endorsement by the U.S. Government. This database, identified as "Geologic map of the Corona North 7.5' quadrangle, Riverside and San Bernardino Counties, California" has been approved for release and publication by the Director of the USGS.

U.S. DEPARTMENT OF INTERIOR

U.S. GEOLOGICAL SURVEY

\author{
${ }^{1}$ U.S. Geological Survey \\ Department of Earth Sciences \\ University of California \\ Riverside CA 92521 \\ ${ }^{2}$ Deceased \\ ${ }^{3}$ California Division of Mines and Geology \\ 107 South Broadway \\ Los Angeles, CA 90012
}




\title{
TABLE OF CONTENTS
}

\author{
Introduction \\ General \\ How to obtain paper plots \\ Database contents \\ Data package \\ Plot package \\ Other files \\ Software utilities \\ How to obtain the digital files \\ Digital databases \\ Postscript plot files \\ Portable Document Format (.pdf) files \\ How to extract the geologic map database from the tar files \\ Digital database \\ Postscript plot files \\ How to convert the ARC/INFO interchange (export) files \\ Digital geologic map specifications \\ Digital compilation \\ Base map \\ Spatial resolution \\ Map accuracy standards \\ Faults and landslides \\ Database specifics \\ General \\ Lines \\ Polygons \\ Points
}

References

\section{INTRODUCTION}

\section{General}

Open-File Report 02-22 contains a digital geologic map database of the Corona North 7.5' quadrangle, Riverside and San Bernardino Counties, California that includes:

1. ARC/INFO (Environmental Systems Research Institute, http://www.esri.com) version 7.2.1 coverages of the various elements of the geologic map.

2. A Postscript file to plot the geologic map on a topographic base, and containing a Correlation of Map Units diagram (CMU), a Description of Map Units (DMU), and an index map.

3. Portable Document Format (.pdf) files of:

a. This Readme; includes in Appendix I, data contained in crn_met.txt

b. The same graphic as plotted in 2 above. Test plots have not produced precise 1:24,000scale map sheets. Adobe Acrobat page size setting influences map scale.

The Correlation of Map Units and Description of Map Units is in the editorial format of USGS Geologic Investigations Series (I-series) maps but has not been edited to comply with I-map standards. Within the geologic map data package, map units are identified by standard geologic map criteria such as formationname, age, and lithology. Where known, grain size is indicated on the map by a subscripted letter or letters following the unit symbols as follows: lg, large boulders; b, boulder; g, gravel; a, arenaceous; s, silt; c, clay; e.g. $\mathrm{Qyf}_{\mathrm{a}}$ is a predominantly young alluvial fan deposit that is arenaceous. Multiple letters are used for more specific identification or for mixed units, e.g., Qfy $\mathrm{sa}_{\mathrm{sa}}$ is a silty sand. In some cases, mixed units are 
indicated by a compound symbol; e.g., Qyf ${ }_{2 s c}$. Marine deposits are in part overlain by local, mostly alluvial fan, deposits and are labeled Qomf. Grain size follows f.

Even though this is an Open-File Report and includes the standard USGS Open-File disclaimer, the report closely adheres to the stratigraphic nomenclature of the U.S. Geological Survey. Descriptions of units can be obtained by viewing or plotting the .pdf file ( $3 \mathrm{~b}$ above) or plotting the postscript file ( 2 above).

This Readme file describes the digital data, such as types and general contents of files making up the database, and includes information on how to extract and plot the map and accompanying graphic file. Metadata information can be accessed at http://geo-nsdi.er.usgs.gov/metadata/open-file/02-22 and is included in Appendix I of this Readme.

\section{HOW TO OBTAIN PAPER PLOTS}

For those having access to large-format plotters such as HP650C, HP755C, and HP2500C, plots may be made directly from the included plot file.

\section{DATABASE CONTENTS}

The files constituting the geologic map database of this Open-File Report are listed below along with the interchange files from which they were extracted.

\section{Data Package}

All files listed below are in a compressed tar file named crn.tar.gz (2.9 Mb); see section below titled, SOFTWARE UTILITES.

$\begin{array}{lll}\begin{array}{l}\text { ARC/INFO } \\ \text { interchange files }\end{array} & \begin{array}{l}\text { Corona North } \\ \text { coverages }\end{array} & \underline{\text { Contains }} \\ \text { crn_geo.e00 } & \text { crn_geo } & \text { Contacts, faults, geologic unit labels } \\ \text { crn_ano.e00 } & \text { crn_ano } & \begin{array}{l}\text { Annotation subclasses: } \\ \text { GEO (for plotting unit labels) } \\ \end{array} \\ & \text { FAULT (for plotting fault names) } \\ & \text { MOUNTAIN (for plotting peak names) } \\ \text { crn_str.e00 } & \text { crn_str } & \begin{array}{l}\text { Leaders } \\ \text { Attitudes and their dip values. Dip values plotted } \\ \text { as annotation. }\end{array}\end{array}$

The directory, info/, is produced in the process of importing interchange files to ARC coverages in ARC/INFO. The crn (Corona North) info/ directory contains:

$\underline{\text { Feature Attribute Tables }}$

Polygon attribute table crn_geo.pat
crn_geo.aat
crn_ano.aat
crn_str.pat

Point attribute table 


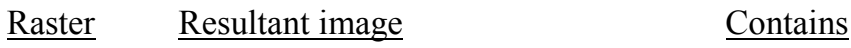

$\underline{\text { file }}$

crn.tif Corona North base map Topographic base from 500 dpi scan of

USGS Corona North 7.5' quadrangle, 1967

\section{Plot Package}

PostScript plot files of the geologic map and explanation; please see section below titled, SOFTWARE UTILITIES for additional information.

Compressed file $\quad \underline{\text { Resultant image } \quad \text { Contains }}$

crn_map.ps.gz crn_map.ps

PostScript plot file of geologic map and CMU/DMU

The Postscript file is compressed using winzip.

The uncompressed Postscript file crn_map.ps will plot a 1:24,000 scale, full color geologic map of the Corona North quadrangle on the topographic base. A detailed CMU diagram, a DMU are included on the sheet. The sheet is in the editorial format of the U.S. Geological Survey's Geologic Investigations (I) map series, and is approximately 47 X 31 inches in size. The map sheet has been successfully plotted on Hewlett-Packard large-format plotters, models HP650C, HP755C, and HP2500C.

\section{Symbols Package}

Files in the plot package have been prepared to produce optimum plots using the shade, line, and marker sets listed below; these symbol sets and supporting fonts are included in a compressed tar file named symbols.tar.gz (0.04 Mb); see section below titled SOFTWARE UTILITIES.

$\begin{array}{ll}\text { geoSCAMP2.lin } & \text { Lineset } \\ \text { geoSCAMP2.mrk } & \text { Markerset for points } \\ \text { alc1.shd } & \text { Colors } \\ \text { geology2.shd } & \text { Pattern fills } \\ \text { fnt026 } & \text { Font required for geoSCAMP2.lin } \\ \text { fnt037 } & \text { Font required for geoSCAMP2.mrk } \\ \text { fnt035 } & \text { Font required for geology2.shd }\end{array}$

Special geologic characters used in unit designations are from the Geoage font group and may be obtained at the following web site:

$\begin{array}{ll}\text { Server: } & \text { onyx.wr.usgs.gov } \\ \text { UserID: } & \text { anonymous } \\ \text { Password: } & \text { Your e-mail address } \\ \text { Directory: } & \text { pub/wpg/supplies/geoage }\end{array}$

\section{Other files}

\author{
README.pdf \\ crn_map.pdf
}

This document

Postscript plot file of geologic map and CMU/DMU 


\section{SOFTWARE UTILITIES}

Files which have .gz file extension were compressed using gzip. Gzip utilities are available free of charge via the Internet at the gzip home page, http://www.gzip.org. Files with a .zip file extension were compressed using WinZip, available at http://www.winzip.com.

The data package and symbols package are additionally bundled into a single tar (tape archive) file. The individual files must be extracted using a tar utility, available free of charge via the Internet through links on the Common Internet File Formats page, http://www.matisse.net/files/format.html. One such utility is WinZip, available at http://www.winzip.com.

\section{HOW TO OBTAIN THE DIGITAL FILES}

The export files, and subsequently the data and plot files, constituting the geologic map database of this Open-File Map may be obtained in two ways, both over the Internet.

1. The files can be obtained via the Web from Western Region Geologic Information Server. Go to the web page at http:/geopubs.wr.usgs.gov/open-file/of02-22 and follow the directions to download the files.

2. The files can also be obtained by anonymous ftp over the Internet from wrgis.wr.usgs.gov. The files are located in the directory /pub/open-file/. Be sure to use binary transfer mode or ASCII mode for individual .e00 (ARC interchange file format) files.

\section{HOW TO EXTRACT THE GEOLOGIC MAP DATABASE FROM THE TAR FILE}

\section{Digital database}

After downloading the files, they must be uncompressed using a gzip utility such as gzip itself or WinZip. The data files must then be extracted using a tar utility or Winzip.

This process will create a directory, crn/, that will contain the ARC/INFO interchange files and supporting files. The directory should contain the following files:

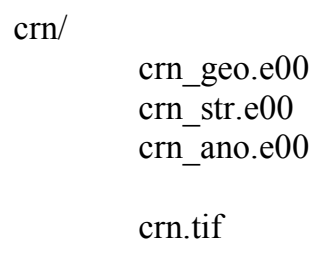

The symbols.tar.gz file is imported using the same methods as for the crn.tar.gz file. It will create a directory, symbols/ that will contain the following files:

geoSCAMP2.lin
geoSCAMP2.mrk
alc1.shd
geology2.shd
fnt026
fnt037
fnt035


The following are not included in the database tar file, and are downloaded separately.

$$
\begin{aligned}
& \text { crn_map.ps.gz } \\
& \text { README.pdf } \\
& \text { crn_map.pdf }
\end{aligned}
$$

\section{Postscript plot files}

Make a 14.5 MB uncompressed file, crn_map.ps (plot of complete map), by typing gzip -d crn_map.ps.gz (or use gzip utility of choice).

\section{Portable Document Format (.pdf) files}

PDF files are not stored as gzip files. They are accessed using Adobe Acrobat Reader software, available free from the Adobe website http://www.adobe.com. Follow instructions at the website to download and install the software. Acrobat Reader contains an on-line manual and tutorial.

\section{HOW TO CONVERT THE ARC/INFO INTERCHANGE (EXPORT) FILES}

The ARC interchange (.e00) files are converted to ARC coverages using the ARC command IMPORT.

ARC interchange files can also be read by some other Geographic Information Systems, including ArcView (ESRI) and MapInfo (http://www.mapinfo.com), (Environmental Systems Research Institute, Inc., 1998). Please consult your GIS documentation to see if you can use ARC interchange files and the procedure to import them.

\section{DIGITAL GEOLOGIC MAP SPECIFICATIONS}

\section{Digital compilation}

The geologic map information was hand digitized from a base-stable original (ink on a greenline) of the geologic map at 1:24,000 scale. Digital tics were placed by hand at latitude/longitude intersections. The lines, points, and polygons were edited using standard ARC/INFO commands, and in some places, interactively by hand using graphical user interface ALACARTE (Fitzgibbon, 1991, Fitzgibbon and Wentworth, 1991, Wentworth and Fitzgibbon, 1991). Digitization and editing artifacts significant enough to display at a scale of 1:24,000 were corrected.

\section{Base map}

The base map image (crn.tif) was prepared by scanning a scale-stable clear film of the U.S. Geological Survey, 1:24,000 Corona North 7.5' quadrangle (1967) topographic map. Scanning was done using an Anatech Eagle 4080 monochrome 800 dpi scanner; at a resolution of 500 dpi. The raster scan was converted to a monochromatic image in ARC/INFO, and registered and rectified to the Corona North 7.5' quadrangle. No elements of the base layer are attributed. The base map is provided for reference only.

\section{Spatial resolution}

Use of this digital geologic map database should not violate the spatial resolution of the data. Although the digital form of the data removes the constraint imposed by the scale of a paper map, the detail and accuracy inherent in map scale are also present in the digital data. The fact that this database was edited at a scale of 1:24,000 means that higher resolution information is not generally present in the dataset. Plotting at scales larger than 1:24,000 will not yield greater real detail, although it may reveal fine-scale irregularities above the intended resolution of the database. Similarly, although higher resolution data is 
incorporated at a few places, the resolution of the combined output will be limited by the lower resolution data.

\section{Map accuracy standards}

Until uniform National geologic map standards are developed and adopted, lines and points on SCAMP 1:24,000 scale geologic maps that are located to within 15 meters, relative to accurately located features on the base map, are considered to meet map accuracy standards. Dashed lines, indicated in the database as approximately located or inferred, are generally located within 30 meters, relative to accurately located features on the base map.

\section{Faults and landslides}

This database is sufficiently detailed to identify and characterize many actual and potential geologic hazards represented by faults and landslides, but it is not sufficiently detailed for site-specific determinations. Faults shown do not take the place of fault rupture hazard zones designated by the California State Geologist (see Hart, 1998).

\section{Database specifics}

General--The map database consists of ARC/INFO format coverages which are stored in polyconic projection (Table 1), and a series of data tables. Digital tics define a 2.5 minute grid of latitude and longitude in the geologic coverages corresponding to the 2.5 minute tic grid on the topographic base map.

$\begin{array}{ll}\text { Table 1 --- } & \text { Map Projection } \\ \text { Projection } & \text { Polyconic } \\ \text { Datum } & \text { NAD27 } \\ \text { Zunits } & \text { No } \\ \text { Units } & \text { Meters } \\ \text { Spheroid } & \text { Clark 1866 } \\ \text { X shift } & 0.000000000 \\ \text { Y shift } & 0.000000000 \\ \text { Parameters } & -1173345.000 \text { longitude of central meridian } \\ & 335230.00 \text { latitude of projections origin } \\ & 0.00000 \text { false easting (meters) } \\ & 0.00000 \text { false northing (meters) }\end{array}$

The content of the geologic database can be described in terms of feature classes that include lines, points, and areas that compose the map. See the metadata text file (Appendix I) for detailed descriptions.

Lines - Lines are recorded as strings of arcs and are described in an arc attribute (.aat) table. Complete lists of the line types (LTYPE) used in the quadrangle are available in Appendix I. They represent contacts and faults, which define the boundaries of map units and map boundaries.

Polygons --- Geologic map units (polygons) are described in the polygon attribute (.pat) table (details in Appendix I). For traditional descriptions of the map units, see the Portable Document Format file crn_map.pdf or the Postscript map plot, crn_map.ps. A list of all map units in the database is given in Appendix I. 
Points - Point information (attitudes of planar and linear features) is recorded as coordinate and related information. Complete lists of the point types (PTTYPE) used in the point coverage are available in Appendix I.

\section{REFERENCES}

Environmental Systems Research Institute, Inc, 1991, ARC/INFO command references 6.0: Proprietary software manual

Fitzgibbon, T.T., 1991, ALACARTE installation and system manual (version 1.0): U.S. Geological Survey, Open-File Report 91-587B

Fitzgibbon, T.T., and Wentworth, C.M., 1991, ALACARTE user interface - AML code and demonstration Maps (version 1.0): U.S. Geological Survey, Open-File Report 91-587A

Wentworth, C.M., and Fitzgibbon, T.T., 1991, ALACARTE user manual (version 1.0): U.S. Geological Survey Open-File Report 91-587C

\section{APPENDIX I (original metadata text)}

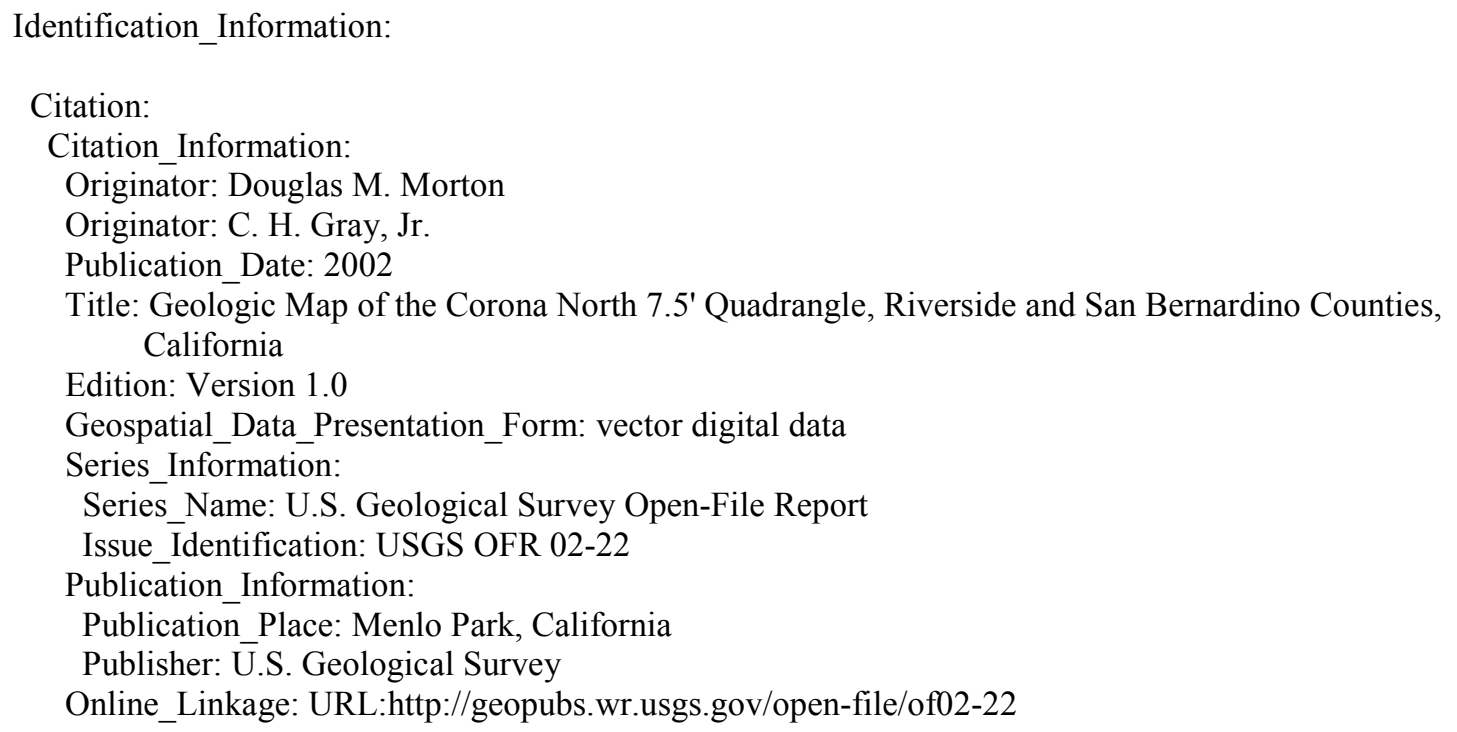

Description:

\section{Abstract:}

This data set maps and describes the geology of the Corona North 7.5' quadrangle, Riverside and San Bernardino Counties, California. Created using Environmental Systems Research Institute's ARC/INFO software, the data base consists of the following items: (1) a map coverage containing geologic contacts and units, (2) a coverage containing structural data, (3) a coverage containing geologic unit annotation and leaders, and (4) attribute tables for geologic units (polygons), contacts (arcs), and site-specific data (points). In addition, the data set includes the following graphic and text products: (1) a postscript graphic plot-file containing the geologic map, topography, cultural data, a Correlation of Map Units (CMU) diagram, a Description of Map Units (DMU), and a key for point and line symbols, and (2) PDF files of the Readme (including the metadata file as an appendix), and the graphic produced by the Postscript plot file.

The Corona North quadrangle is located near the northern end of the Peninsular Ranges Province. All but the southeastern tip of the quadrangle is within the Perris block, a relatively stable, rectangular in plan 
area located between the Elsinore and San Jacinto fault zones. The southeastern tip of the quadrangle is barely within the Elsinore fault zone.

The quadrangle is underlain by Cretaceous plutonic rocks that are part of the composite Peninsular Ranges batholith. These rocks are exposed in a triangular-shaped area bounded on the north by the Santa Ana River and on the south by Temescal Wash, a major tributary of the Santa Ana River. A variety of mostly silicic granitic rocks occur in the quadrangle, and are mainly of monzogranite and granodioritic composition, but range in composition from micropegmatitic granite to gabbro. Most rock units are massive and contain varying amounts of meso- and melanocratic equant-shaped inclusions. The most widespread granitic rock is monzogranite of the Cajalco pluton, a large pluton that extends some distance south of the quadrangle. North of Corona is a body of micropegmatite that appears to be unique in the batholith rocks.

Diagonally bisecting the quadrangle is the Santa Ana River. North of the Santa Ana River alluvial deposits are dominated by the distal parts of alluvial fans emanating from the San Gabriel Mountains north of the quadrangle. Widespread areas of the fan deposits are covered by a thin layer of wind blown sand.

Alluvial deposits in the triangular-shaped area between the Santa Ana River and Temescal Wash are quite varied, but consist principally of locally derived older alluvial fan deposits. These deposits rest on remnants of older, early Quaternary or late Tertiary age, nonmarine sedimentary deposits that were derived from both local sources and sources as far away as the San Bernardino Mountains. These deposits in part were deposited by an ancestral Santa Ana River. Older are a few scattered remnants of late Tertiary (Pliocene) marine sandstone that include some conglomerate lenses. Clasts in the conglomerate include siliceous volcanic rocks exotic to this part of southern California. This sandstone was deposited as the southeastern-most part of the Los Angeles sedimentary marine basin and was deposited along a rocky shoreline developed in the granitic rocks, much like the present day shoreline at Monterey, California. Most of the sandstone and granitic paleoshoreline features have been removed by quarrying and grading in the area of Porphyry north to Highway 91. Excellent exposures in highway road cuts still remain on the north side of Highway 91 just east of the 91-15 interchange and on the east side of U.S. 15 just north of the interchange.

South of Temescal Wash is a series of both younger and older alluvial fan deposits emanating from the Santa Ana Mountains to the southeast. In the immediate southwest corner of the quadrangle is a small exposure of sandstone and pebble conglomerate of the Sycamore Canyon member of the Puente Formation of early Pliocene and Miocene age and sandstone and conglomerate of undivided Sespe and Vaqueros Formations of early Miocene, Oligocene, and late Eocene age.

The geologic map data base contains original U.S. Geological Survey data generated by detailed field observation recorded on 1:24,000 scale aerial photographs. The map was created by transferring lines from the aerial photographs to a 1:24,000 scale topographic base. The map was digitized and lines, points, and polygons were subsequently edited using standard ARC/INFO commands. Digitizing and editing artifacts significant enough to display at a scale of 1:24,000 were corrected. Within the database, geologic contacts are represented as lines (arcs), geologic units are polygons, and site-specific data as points. Polygon, arc, and point attribute tables (.pat, .aat, and .pat, respectively) uniquely identify each geologic datum.

Purpose: The data set for the Corona North 7.5' quadrangle was prepared under the U.S. Geological Survey Southern California Areal Mapping Project (SCAMP) as part of an ongoing effort to develop a regional geologic framework of southern California, and to utilize a Geographic Information System (GIS) format to create regional digital geologic databases. These regional databases are being developed as contributions to the National Geologic Map Database of the National Cooperative Geologic Mapping Program of the USGS.

Supplemental_Information: none

Time_Period_of_Content:

Time_Period_Information:

Single Date/Time:

Calendar_Date: 2002

Currentness_Reference: New data

Status:

Progress: Complete

Maintenance_and_Update_Frequency: As Needed 


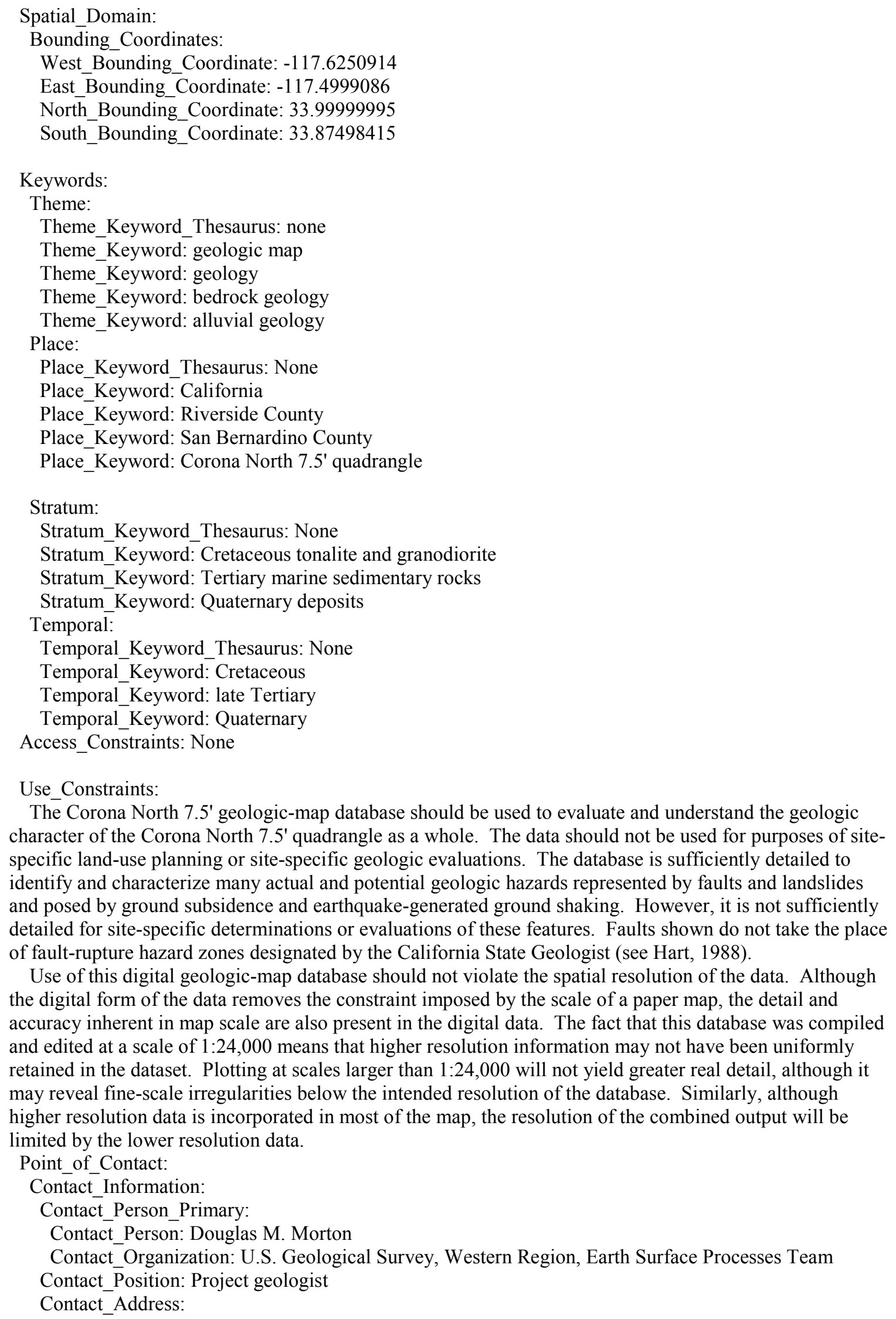

The Corona North 7.5' geologic-map database should be used to evaluate and understand the geologic character of the Corona North 7.5' quadrangle as a whole. The data should not be used for purposes of sitespecific land-use planning or site-specific geologic evaluations. The database is sufficiently detailed to identify and characterize many actual and potential geologic hazards represented by faults and landslides and posed by ground subsidence and earthquake-generated ground shaking. However, it is not sufficiently detailed for site-specific determinations or evaluations of these features. Faults shown do not take the place of fault-rupture hazard zones designated by the California State Geologist (see Hart, 1988).

Use of this digital geologic-map database should not violate the spatial resolution of the data. Although the digital form of the data removes the constraint imposed by the scale of a paper map, the detail and accuracy inherent in map scale are also present in the digital data. The fact that this database was compiled and edited at a scale of 1:24,000 means that higher resolution information may not have been uniformly retained in the dataset. Plotting at scales larger than 1:24,000 will not yield greater real detail, although it may reveal fine-scale irregularities below the intended resolution of the database. Similarly, although higher resolution data is incorporated in most of the map, the resolution of the combined output will be limited by the lower resolution data.

Point_of_Contact:

Contact_Information:

Contact_Person_Primary:

Contact_Person: Douglas M. Morton

Contact_Organization: U.S. Geological Survey, Western Region, Earth Surface Processes Team

Contact_Position: Project geologist

Contact_Address: 
Address_Type: mailing address

Address: U.S. Geological Survey

Address: Department of Earth Sciences

Address: University of California, Riverside

City: Riverside

State_or_Province: California

Postal_Code: 92521

Country: United States of America

Contact Voice Telephone: (909) 276-6397

Contact_Facsimile_Telephone: (909) 276-6295

Contact_Electronic_Mail_Address: scamp@usgs.gov

Data_Set_Credit: Geologic mapping and digital preparation of this report were sponsored jointly by (1)

the National Cooperative Geologic Mapping Program of the U.S. Geological Survey, (2) the California

Division of Mines and Geology, and (3) the Southern California Areal Mapping Project (SCAMP).

Native_Data_Set_Environment:

SunOS, 5.8, sun4m UNIX

ARC/INFO version 7.2.1

Cross_Reference:

Citation_Information:

Originator: Morton, D.M.

Publication_Date: 1999

Title: Preliminary digital geologic map of the Santa Ana 30'x60' quadrangle, southern California, version 1.0.

Geospatial_Data_Presentation_Form: vector digital data

Series_Information:

Series_Name: U.S. Geological Survey Open-File Report

Issue_Identification: USGS OF 99-172

Publication_Information:

Publication_Place: California

Publisher: U.S. Geological Survey

Online_Linkage: http://geopubs.wr.usgs.gov/open-file/of99-172

Data_Quality_Information:

Attribute_Accuracy:

Attribute_Accuracy_Report:

Geologic-map units in the Corona North quadrangle database were described using standard field methods. Consistent with these methods, the database author has assigned standard geologic attributes to geologic lines, points, and polygons identified in the database.

Nation-wide geologic-map accuracy standards have not been developed and adopted by the U.S. Geological Survey and other earth-science entities. Until such standards are adopted, the SCAMP project has developed internal map-accuracy standards for 1:24,000-scale geologic maps produced by the project.

Geologic lines and points on 1:24,000 scale geologic maps are judged to meet SCAMP's internal mapaccuracy standards if they are located to within $+/-15$ meters, relative to topographic or cultural features on the base map.

On any derivative geologic-map plot, line data that are judged to meet the SCAMP internal mapaccuracy standard are denoted by solid lines; line data that may not meet the SCAMP internal mapaccuracy standard are denoted by dashed or dotted lines. There is no cartographic device for denoting the map-accuracy for geologic-point data (e.g., symbols representing bedding, foliation, lineations, etc.).

Logical_Consistency_Report:

Polygon and chain-node topology present.

The areal extent of the map is represented digitally by an appropriately projected (polyconic projection), mathematically generated box. Consequently, polygons intersecting the lines that comprise the map boundary are closed by that boundary. Polygons internal to the map boundary are completely enclosed by line segments which are themselves a set of sequentially numbered coordinate pairs. Point data are represented by coordinate pairs. 
Completeness_Report: The geologic map database of the Corona North 7.5' quadrangle contains new data that have been subjected to rigorous review and are a substantially complete representation of the current state of knowledge concerning the geology of the quadrangle.

Positional_Accuracy:

Horizontal_Positional_Accuracy:

Horizontal_Positional_Accuracy_Report: The maximum transformation RMS error acceptable for a 7.5' quadrangle transformation and data input is 0.003 (1.8 meters). Horizontal positional accuracy was checked by visual comparison of hard-copy plots with base-stable source data.

Lineage:

Process_Step:

Process_Description: Field mapping and aerial photograph interpretation; iterative process (D.M. Morton).

Process_Date: $1977 ; 1996$

Process_Step:

Process_Description: Field mapping and aerial photograph interpretation; iterative process (C.H. Gray). Process_Date: 1970; 1995

Process_Step:

Process_Description: Digitization of geologic linework and point data from a scale-stable cartographic base of quadrangle. ARC/INFO database established; cleanup of artifacts; polygon, arc, and point attribute tables established. Digitizing and editing artifacts significant enough to display at a scale of 1:24,000 were corrected (K.R. Bovard and M.L. Dawson).

Process_Date: 1999-2001

Process_Step:

Process_Description: Description of map units and correlation of map units (K.C. Corriea).

Process_Date: 2001

Process_Step:

Process_Description:

First draft of metadata created by mwatson using

FGDCMETA.AML ver. 1.2 05/14/98 on ARC/INFO data set

/scamp26/mwatson/crn/crn_geo

Process_Date: 20011126

Spatial_Data_Organization_Information:

Direct_Spatial_Reference_Method: Vector

Point_and_Vector_Object_Information:

SDTS_Terms_Description:

SDTS_Point_and_Vector_Object_Type: Point

Point_and_Vector_Object_Count: 232

SDTS_Point_and_Vector_Object_Type: String

Point_and_Vector_Object_Count: 574

SDTS_Point_and_Vector_Object_Type: GT-polygon composed of chains

Point_and_Vector_Object_Count: 233

Spatial_Reference_Information:

Horizontal_Coordinate_System_Definition:

Planar:

Map_Projection:

Map_Projection_Name: Polyconic

Polyconic:

Latitude_of_True_Scale: $\quad 33.875$

Longitude_of_Central_Meridian: -117.5625

False_Easting: 0.00000 
False_Northing: 0.00000

Planar_Coordinate_Information:

Planar_Coordinate_Encoding_Method: coordinate pair

Coordinate_Representation:

Abscissa_Resolution: 1.000366806984

Ordinate Resolution: 1.000366806984

Planar_Distance_Units: Meters

Geodetic_Model:

Horizontal_Datum_Name: North American Datum of 1927

Ellipsoid_Name: Clarke 1866

Semi-major_Axis: 6378206.4

Denominator_of_Flattening_Ratio: 294.98

Entity_and_Attribute_Information:

Overview_Description:

Entity_and_Attribute_Overview:

Version 1.0 of the Corona North 7.5' quadrangle comprises three ARC/INFO coverages, of which two contain geologic data, and one contains cartographic features: crn_geo (geology), crn_str (structural data), and crn_ano (annotation and leaders).

Geologic data represented by line entities and the polygons they delineate are contained in the coverage CRN_GEO. For display purposes, the annotation coverage contains three annotation subclasses: anno.geo contains unit labels, anno.fault contains fault names, and anno.mountain contains peak names.

Geological point data includes site-specific information describing the types and the orientation of bedding, foliation, and lineations. Annotation is respective dip and plunge values associated with individual point data.

$>$

$>$ CRN GEO.PAT:

$>$

$>$ COLUMN ITEM NAME WIDTH OUTPUT TYPE N.DEC ALTERNATE NAME

$>1 \quad$ AREA

$>5$ PERIMETER

$>9$ CRN_GEO\#

$>13$ CRN_GEO-ID

$>17 \quad$ LABL

$>52 \quad$ SHD

$>55 \quad$ PLABL

$>90 \quad$ SHDFIL

$>93 \quad$ NAME

$>$

$>$

$>$ CRN_GEO.AAT:

$>$

$>$ COLUMN

$>1 \quad$ FNODE\#

$>5$ TNODE\#

$>9$ LPOLY\#

$>13 \quad$ RPOLY\#

$>17$ LENGTH

$>21$ CRN_GEO\#

$>25$

$>29$

CRN_GEO-ID

$\begin{array}{llll}4 & 12 & F & 3\end{array}$

$>64$

LTYPE

$>$

$>$

Entity_and_Attribute_Detail_Citation: none 
Detailed_Description:

Entity_Type:

Entity_Type_Label: crn_geo.pat

Entity_Type_Definition: Geologic units (LABL) and their corresponding names (NAME) identified in the Corona North 7.5' quadrangle

Attribute:

Attribute_Label: LABL

Attribute_Definition: geologic map unit label, in plain text

Attribute Domain Values:

Enumerated_Domain:

Enumerated_Domain_Value: Qaf

Enumerated_Domain_Value_Definition: Artificial fill

Enumerated_Domain:

Enumerated Domain Value: Qwa

Enumerated Domain Value Definition: Very young wash deposits, arenaceous

Enumerated_Domain:

Enumerated Domain Value: Qywa

Enumerated_Domain_Value_Definition: Young wash deposits, arenaceous

Enumerated_Domain:

Enumerated_Domain_Value: Qyfa

Enumerated Domain Value Definition: Young alluvial fan deposits, arenaceous

Enumerated_Domain:

Enumerated_Domain_Value: Qyfg

Enumerated_Domain_Value_Definition: Young alluvial fan deposits, gravel

Enumerated_Domain:

Enumerated_Domain_Value: Qyflg

Enumerated_Domain_Value_Definition: Young alluvial fan deposits, Unit 1, gravel

Enumerated Domain:

Enumerated_Domain_Value: Qyaa

Enumerated_Domain_Value_Definition: Young alluvial channel deposits, arenaceous

Enumerated_Domain:

Enumerated_Domain_Value: Qye

Enumerated_Domain_Value_Definition: Young eolian deposits

Enumerated Domain:

Enumerated_Domain_Value: Qowa

Enumerated_Domain_Value_Definition: Old wash deposits, arenaceous

Enumerated_Domain:

Enumerated Domain Value: Qofa

Enumerated Domain ${ }^{-}$Value Definition: Old alluvial fan deposits, arenaceous

Enumerated Domain:

Enumerated_Domain_Value: Qofg

Enumerated_Domain_Value_Definition: Old alluvial fan deposits, gravel

Enumerated_Domain:

Enumerated_Domain_Value: Qoflg

Enumerated_Domain_Value_Definition: Old alluvial fan deposits, Unit 1, gravel

Enumerated Domain:

Enumerated Domain Value: Qoa

Enumerated_Domain_Value_Definition: Old alluvial channel deposits

Enumerated_Domain:

Enumerated_Domain_Value: Qoaa

Enumerated_Domain_Value_Definition: Old alluvial channel deposits, arenaceous

Enumerated Domain:

Enumerated Domain Value: Qova

Enumerated_Domain_Value_Definition: Old alluvial valley deposits, arenaceous

Enumerated Domain:

Enumerated_Domain_Value: Qvofa 
Enumerated_Domain_Value_Definition: Very old alluvial fan deposits, arenaceous

Enumerated_Domain:

Enumerated_Domain_Value: Qvofg

Enumerated_Domain_Value_Definition: Very old alluvial fan deposits, gravel

Enumerated_Domain:

Enumerated_Domain_Value: Qvoaa

Enumerated_Domain_Value_Definition: Very old alluvial channel deposits, arenaceous

Enumerated_Domain:

Enumerated_Domain_Value: QTn

Enumerated_Domain_Value_Definition: Late Cenozoic sedimentary rocks in Norco area

Enumerated_Domain:

Enumerated_Domain_Value: Tns

Enumerated_Domain_Value_Definition: Sandstone of Norco area

Enumerated Domain:

Enumerated Domain_Value: Tpsc

Enumerated_Domain_Value_Definition: Sycamore Canyon Member of Puente Formation

Enumerated_Domain:

Enumerated_Domain_Value: Tvs

Enumerated_Domain_Value_Definition: Vaqueros and Sespe Formations, undifferentiated

Enumerated Domain:

Enumerated Domain Value: Kmp

Enumerated_Domain_Value_Definition: Micropegmatite granite of Gavilan Ring Complex

Enumerated_Domain:

Enumerated_Domain_Value: Kmpc

Enumerated_Domain_Value_Definition: Micropegmatite and granodiorite of Cajalco pluton, undifferentiated

Enumerated_Domain:

Enumerated_Domain_Value: Krg

Enumerated_Domain_Value_Definition: Granite of the Riverside area

Enumerated_Domain:

Enumerated_Domain_Value: Kmhg

Enumerated_Domain_Value_Definition: Mount Hole Granodiorite

Enumerated_Domain:

Enumerated Domain Value: Klst

Enumerated_Domain_Value_Definition: La Sierra Tonalite

Enumerated_Domain:

Enumerated_Domain_Value: Kcg

Enumerated_Domain_Value_Definition: Monzogranite of Cajalco Pluton

Enumerated_Domain:

Enumerated_Domain_Value: Kcgb

Enumerated_Domain_Value_Definition: Granodiorite and gabbro of Cajalco Pluton, undifferentiated

Enumerated_Domain:

Enumerated_Domain_Value: Kqd

Enumerated_Domain_Value_Definition: Quartz diorite of Peninsular Ranges batholith

Enumerated_Domain:

Enumerated_Domain_Value: Kd

Enumerated_Domain_Value_Definition: Diorite of Peninsular Ranges batholith, undifferentiated

Enumerated_Domain:

Enumerated_Domain_Value: Kgb

Enumerated_Domain_Value_Definition: Gabbro of Peninsular Ranges batholith

Attribute:

Attribute_Label: PLABL

Attribute_Definition: Geological map unit label used to generate plot labels with relevant stratigraphic symbols. The geologic units with LABL designating Mesozoic (Mz) have keystroke substitute characters, \}, that call their corresponding symbols from the Geoage Font Group. Geologic map unit labels will plot 
on derivative map plots with appropriate stratigraphic symbols if PLABL is used as the source for unit labels.

Attribute:

Attribute Label: SHD

Attribute_Definition: polygon color (as integer value) from shadeset alc1.shd

Attribute:

Attribute_Label: SHDFIL

Attribute_Definition: polygon fill pattern (as integer value) from shadeset geology2.shd

Attribute:

Attribute_Label: NAME

Attribute_Definition: Geologic name of map unit (see list under LABL attribute)

Detailed_Description:

Entity_Type:

Entity_Type_Label: crn_geo.aat

Entity_Type_Definition: Geologic features such as contacts and faults that bound rock-unit polygons

Attribute:

Attribute Label: LTYPE

Attribute_Definition: Description of types of lines on the geologic map (contact, fault).

Attribute_Domain_Values:

Enumerated Domain:

Enumerated Domain Value: map boundary

Enumerated_Domain_Value: contact, certain

Enumerated_Domain_Value: fault, queried

Enumerated_Domain_Value: fault, concealed

Enumerated_Domain_Value: fault, approx. located

Enumerated_Domain_Value: fault, concealed, queried

Attribute:

Attribute Label: L-SYMB

Attribute_Definition: stores appropriate line symbol value from the lineset geoscamp2.lin

Detailed_Description:

Entity_Type:

Entity_Type_Label: crn_str.pat

Entity_Type_Definition: Geological point data includes site-specific information describing the types

and the orientation of bedding, foliation, and lineation. One annotation subclass is included in the geologic points coverage, CRN_STR which displays the respective dip and plunge values associated with individual point data.

Attribute:

Attribute_Label: PTTYPE

Attribute_Definition: describes type of point data (bedding, horizontal bedding, foliation)

Attribute_Domain_Values:

Enumerated_Domain:

Enumerated_Domain_Value: bedding

Attribute:

Attribute_Label: P-SYMB

Attribute_Definition: Coded integer value that relates point to cartographic point symbol in markerset

Attribute: geoscamp2.mrk

Attribute_Label: STRIKE

Attribute_Definition: Azimuthal strike of planar feature

Attribute:

Attribute_Label: DIP

Attribute_Definition: Dip of planar feature

Detailed_Description:

Entity_Type:

Entity_Type_Label: crn_ano.aat

Entity_Type_Definition: Annotation leaders 
Attribute:

Attribute Label: L-SYMB

Attribute_Definition: Coded integer value (1) that relates arcs to cartographic line symbol in lineset

Distribution_Information: geoscamp2.lin

Distributor:

Contact_Information:

Contact_Organization_Primary:

Contact_Organization: U.S. Geological Survey Information Services

Contact_Address:

Address_Type: mailing address

Address: Box 25286 Denver Federal Center

City: Denver

State_or_Province: Colorado

Postal Code: 80225

Country: USA

Contact Facsimile Telephone: (303)202-4693

Contact_Voice_Telephone: (303)202-4700

Distribution_Liability:

The U.S. Geological Survey (USGS) provides these geographic data "as is." The USGS makes no guarantee or warranty concerning the accuracy of information contained in the geographic data. The USGS further makes no warranties, either expressed or implied as to any other matter whatsoever, including, without limitation, the condition of the product, or its fitness for use lies entirely with the user. Although these data have been processed successfully on computers at the USGS, no warranty, expressed or implied, is made by the USGS regarding the use of these data on any other system, nor does the fact of distribution constitute or imply any such warranty.

In no event shall the USGS have any liability whatsoever for payment of any consequential, incidental, indirect, special, or tort damages of any kind, including, but not limited to, any loss of profits arising out of use of or reliance on the geographic data or arising out of the delivery, installation, operation, or support by USGS.

This digital geologic map database of the Corona North 7.5' quadrangle, 1:24,000 map-scale, and any derivative maps thereof, is not meant to be used or displayed at any scale larger than 1:24,000 (e.g., $1: 12,000)$.

Metadata_Reference_Information:

Metadata_Date: 20011126

Metadata_Review_Date: 20020103

Metadata_Contact:

Contact_Information:

Contact_Organization_Primary:

Contact_Organization: U.S. Geological Survey

Contact_Person: Rachel M. H. Alvarez

Contact_Position: Geologist

Contact_Address:

Address_Type: mailing address

Address: U.S. Geological Survey

Address: Department of Earth Sciences

Address: University of California, Riverside

City: Riverside

State_or_Province: California

Postal_Code: 92521

Country: USA

Contact_Voice_Telephone: (909) 276-6397

Contact_Facsimile_Telephone: (909) 276-6295

Contact_Electronic_Mail_Address: rhauser@usgs.gov

Metadata_Standard_Name: FGDC Content Standards for Digital Geospatial Metadata 
Metadata_Standard_Version: Version of June 8, 1994

Metadata_Access_Constraints: none

Metadata_Use Constraints: none 